\title{
Amphichronic explanation and the life cycle of phonological processes
}

DOI:

10.1093/oxfordhb/9780199232819.013.014

Link to publication record in Manchester Research Explorer

\section{Citation for published version (APA):}

Bermúdez-Otero, R. (2015). Amphichronic explanation and the life cycle of phonological processes. In P.

Honeybone, \& J. C. Salmons (Eds.), The Oxford handbook of historical phonology (pp. 374-399). [22] (Oxford

Handbooks Online). Oxford University Press. https://doi.org/10.1093/oxfordhb/9780199232819.013.014

\section{Published in:}

The Oxford handbook of historical phonology

\section{Citing this paper}

Please note that where the full-text provided on Manchester Research Explorer is the Author Accepted Manuscript or Proof version this may differ from the final Published version. If citing, it is advised that you check and use the publisher's definitive version.

\section{General rights}

Copyright and moral rights for the publications made accessible in the Research Explorer are retained by the authors and/or other copyright owners and it is a condition of accessing publications that users recognise and abide by the legal requirements associated with these rights.

\section{Takedown policy}

If you believe that this document breaches copyright please refer to the University of Manchester's Takedown Procedures [http://man.ac.uk/04Y6Bo] or contact uml.scholarlycommunications@manchester.ac.uk providing relevant details, so we can investigate your claim.

\section{OPEN ACCESS}




\section{Amphichronic explanation and the life cycle of phonological processes}

Ricardo Bermúdez-Otero

University of Manchester

\section{Amphichronic explanation}

Disagreement over the appropriate scope of synchronic and diachronic explanation in linguistics is as old as the Saussurean dichotomy itself (Saussure 1916: part one, ch. III). Without Saussure's insight that languages constitute systems amenable to synchronic analysis, much research into linguistic typology and language universals, whether in the Greenbergian or in the Chomskyan tradition, would scarcely be conceivable; yet Saussure himself appears to have simultaneously subscribed to the neogrammarian belief that sound change operates without regard to its effects upon the linguistic system (e.g. 1916: part three, ch. II, §5), and this idea, as noted by Jakobson (1929), renders the very existence of phonological universals problematic (Kiparsky 1995: 641).

Similarly, current work in phonology offers a wide range of opinion on the relationship between synchrony and diachrony, the issue having become entangled with the debate between rationalist and empiricist approaches to the nature of linguistic knowledge. At one extreme, research in the tradition of classic Optimality Theory (OT, Prince and Smolensky 1993, and see Holt, this volume) commonly treats specific hypotheses about the universal constraint set (CON) as falsified by gaps in factorial typology - a practice which ultimately presupposes that the set of attestable languages can be delimited on purely synchronic grounds. At the opposite extreme, the Evolutionary Phonology programme (Blevins 2004, this volume) elevates the priority of diachronic over synchronic explanation to the status of an epistemological principle (essentially a special case of Ockham's razor), and, although it attributes a range of domaingeneral and even possibly domain-specific abilities to learners, these rarely take a prominent role in actual proposals and are rarely elaborated in detail.

Some lines of enquiry seek a more complex and nuanced understanding of the interplay between synchronic and diachronic factors in the genesis of crosslinguistic phonological patterns. This type of work-which, borrowing Kiparsky's term (2006: 222), I call 'amphichronic'-acknowledges that explanation must proceed in both directions. First, certain fundamental observations about the sorts of phonological innovations attested in the empirical record and about recurrent pathways in the historical evolution of phonological systems can be fully explained only by taking into account the cognitive abilities underpinning the transmission of grammars between individuals and the basic design features of those grammars-in particular, their overall architecture. Only such reasoning can make sense, for example, of the existence of neogrammarian sound change (Labov 2010: ch. 13) and of the life cycle of 
phonological processes (Bermúdez-Otero 2007: 504-5, Bermúdez-Otero and Trousdale 2012: $\S 2$, Ramsammy forthcoming). With such an understanding of phonological change in place, however, many crosslinguistic facts will turn out not to call for enrichments of synchronic theory, but will be seen to emerge from recurrent historical processes. Indeed, we should not be surprised at all if, in many cases, comprehensive accounts of micro- and macro-typological patterns end up cycling repeatedly between synchronic and diachronic explanation.

Needless to say, such an amphichronic outlook is compatible with a broad range of positions on much debated issues such as the nature of phonological markedness (Scheer, this volume). Elaborating Jakobson's (1929) position, for example, Kiparsky (2006) argues that exceptionless universals require the postulation of synchronic cognitive representations of markedness, and that purely emergentist explanations suffice only for typological trends. In contrast, Moreton and Pater (forthcoming a, b) frame the issue in terms of biases: they hypothesize that substantive biases may arise diachronically from properties of the phonetic channel, whereas formal biases, particularly those favouring coarse-grained generalizations, may reflect the cognitive predispositions of the learner (Moreton 2008). Their programme for a Structurally Biased Phonology (Pater and Moreton 2012) differs crucially from that of Evolutionary Phonology in that it incorporates fully formalized and computationally testable proposals concerning the cognitive underpinnings of formal biases. Important though the controversy over markedness is, however, it risks obscuring the need for amphichronic research in other areas of phonology. This chapter illustrates this in two ways.

In $§ 2$, I revisit my assertion that the classical modular feedforward architecture of grammar is essential to understanding the modes of implementation of phonological change and the life cycle of phonological processes (Bermúdez-Otero 2007: 501ff, Bermúdez-Otero and Trousdale 2012: 693ff). The modular feedforward architecture itself has recently been challenged in several ways, and notably by claims that morphological structure can directly affect the application of gradient rules of phonetic implementation (Kawahara 2011: §2.3.3). I show, however, that this appearance often emerges from a side effect of the diachronic life cycle of phonological processes: 'rule scattering' (Bermúdez-Otero 2010, after Robinson 1976). In rule scattering, a process in one component of the grammar gives rise to a new rule at a higher level — fully in line with the life cycle-but without ceasing to apply at the lower level: as a special case, innovative phonological rules do not replace the phonetic rules from which they emerge, but typically coexist with them (Bermúdez-Otero 2007: 506). In this situation, what may pretheoretically be described as a single sound pattern (e.g. English /1/-darkening) turns out in fact to reflect the cumulative effect of several cognate processes simultaneously overlaid within the synchronic grammar, where each individual process impeccably abides by the restrictions of the modular feedforward architecture: only categorical phonological rules apply in morphosyntactically defined domains, and only across-the-board phonetic rules show gradience.

In turn, $\S 3$ explores the consequences of the fact that each new process that enters the grammar through a step in a long-term trajectory of change, such as a lenition pathway or a 
cline of rule generalization, can go through the life cycle of phonological processes on its own. This results in typological trends that may be stated in purely synchronic terms. For example, if two distinct phonological rules within the same grammar perform the same structural change but one subsumes the structural description of the other, then the more general rule is likely to have a wider cyclic domain. Similarly, if two distinct processes of lenition within the same grammar target the same consonant in the same phonologicalenvironment but one causes a more drastic weakening of the consonant than the other, then the more aggressive process is likely to have a wider cyclic domain. Although these tendencies can be stated synchronically, they do not require synchronic explanation; they merely reflect that, ceteris paribus, processes that embarked on their life cycle earlier in historical time are more likely to have reached higher levels in the grammar.

\section{The architecture of grammar and the life cycle of phonological processes}

\subsection{Diachronic predictions of the modular feedforward architecture}

Research has long explored the idea that the synchronic organization of grammars accounts for key facts about phonological change, in particular the existence of neogrammarian regularity and the life cycle of phonological processes. The basic insights date to the dawn of structuralism (Kruszewski 1881). Recent elaborations include works by Kiparsky $(1988,1995)$, Bermúdez-Otero (2007), and Bermúdez-Otero and Trousdale (2012: §2). The latter argue for a grammatical architecture with three crucial properties.

The first is modularity: the grammar consists of a number of separate components, each characterized by its own proprietary set of representations and communicating with adjacent modules through narrowly constrained interfaces (e.g. Bermúdez-Otero 2012: 45-49). The relevant modules are morphology, phonology, and phonetics:

(1)

\begin{tabular}{ll}
\hline Module & Proprietary representations \\
\hline morphology & morphs \\
phonology & discrete phonological objects (e.g. segmental features, prosodic nodes, association lines) \\
phonetics & continuous phonetic dimensions (e.g. formant frequencies, gesture amplitudes and durations) \\
\hline
\end{tabular}

In this view, the morphology selects and concatenates morphs, but cannot alter their phonological content ('Morph Integrity'); see Bermúdez-Otero (2012: 50ff).

Secondly, modules are arranged serially: i.e. information flow at the interfaces is feedforward. Thus, morphology precedes phonology within each derivational cycle, and phonology precedes phonetics. By implication, morphology and phonetics do not share an interface. However, the principle of feedforward derivation holds for the computational theory in Marr's (1982) sense, i.e. describes mappings computed by the grammar. Processing 
implementations may allow varying amounts of cascading activation and feedback (e.g. Rapp and Goldrick 2000, and §2.2, §2.4).

Finally, the phonological module is cyclic and stratified as in Lexical Phonology (Kiparsky 1982) and Stratal OT (Bermúdez-Otero 1999, Kiparsky 2000). In a cyclic derivation, the phonology applies iteratively over a hierarchy of nested domains defined by morphosyntactic structure, starting with the smallest domains and moving outwards. Cyclic domains of different types (stem-level, word-level, phrase-level) are subject to different phonological generalizations. Evidence for this view of the morphosyntax-phonology interface is provided by BermúdezOtero (2011). However, it does not particularly matter here whether we conceive of the phonological cycle as operating in an interactionist or noninteractionist fashion (Scheer 2011: 127ff). Thus, models $(2, a)$ and $(2, b)$ from the late 1980s are equally possible instantiationsamong others - of the modular feedforward architecture assumed here.

a. Interactionist architecture

(Booij and Rubach 1987)

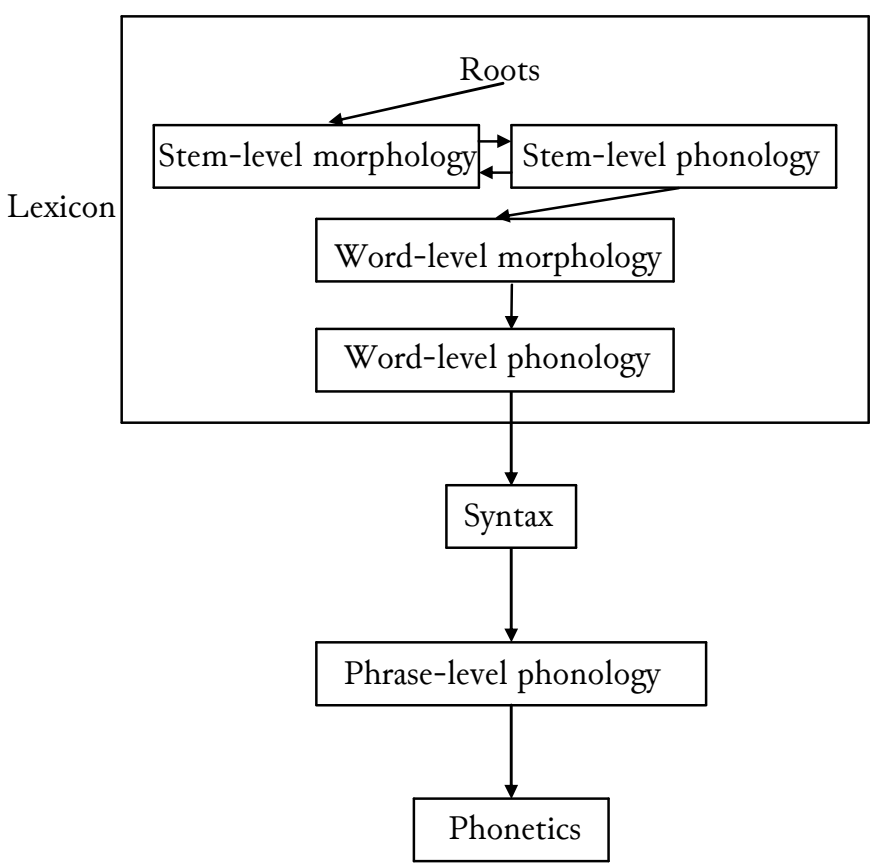

b. Noninteractionist arcbitecture

(Halle and Vergnaud 1987)

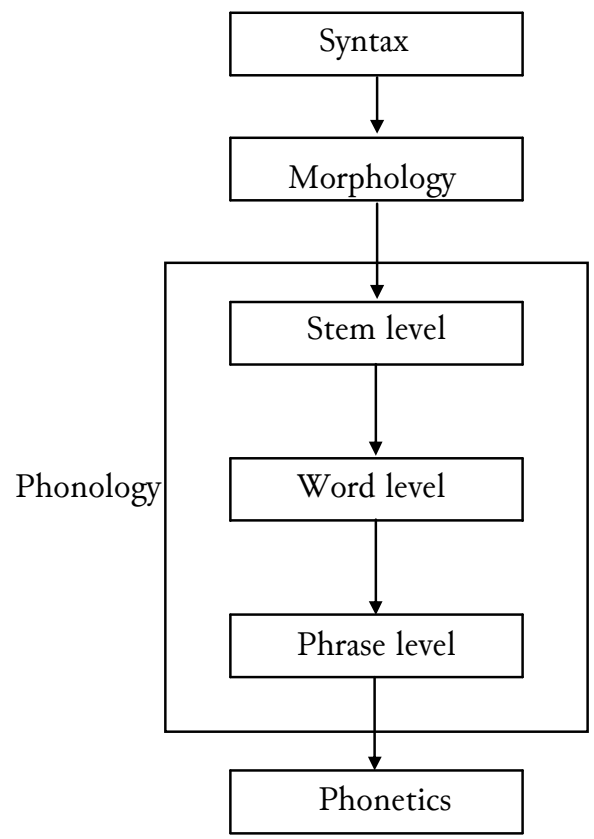

In particular, neither model allows direct interactions between morphology and phonetics.

The modular feedforward architecture makes predictions about phonological change in two major ways. First, it defines an inventory of possible types of changes, distinguished from one another by the factors that may or may not affect their implementation (see BermúdezOtero 2007: 503 et seq., especially (4)). This follows from the null hypothesis that each component of the grammar may undergo innovations independently of the others. If that is the case, then an innovation in one module will manifest itself as a change conditioned by information available to that module alone; conversely, factors to which the module is blind will not affect the implementation of the change. Notably, innovations in phonetic 
implementation give rise to neogrammarian changes: these are phonetically gradient because phonetic rules operate over continuous phonetic dimensions, and they are regular because the phonetic module has access to surface phonological representations (including prosodic structure) but not to lexical entries or to morphosyntactic structure. Neogrammarian change is considered in greater detail in §2.2. Its precise mirror image is lexical diffusion in the classic sense of Wang (1969), i.e. phonetically abrupt and lexically gradual change; see Kiparsky (1988, 1995), Bermúdez-Otero (2007: 508-12), and Phillips (this volume) for a different approach.

Secondly, the modular feedforward architecture predicts the overall direction in which change will advance through the grammar over time: in other words, the architecture lays down the track for the life cycle of phonological processes (Bermúdez-Otero 2007: 504-5; BermúdezOtero and Trousdale 2012: 692-3, 700). This follows from elementary considerations about the mechanism of grammar transmission, including both the construction of grammars by children and the updating of grammars by adults - the latter confined, of course, to those areas of linguistic competence that remain plastic across the individual's lifespan (e.g. Harrington 2006, Sankoff and Blondeau 2007). In both cases, individuals lack direct access to the linguistic representations generated by other individuals' mental grammars; rather, they reconstruct those representations from circumambient speech, starting, in the case of phonetic and phonological competence, with raw acoustic data. As a result, data reanalysis leading to representation restructuring becomes a primary mechanism for innovation: in neogrammarian change, for example, raw acoustic data are reanalysed in such a way that the targets assigned by phonetic rules to surface phonological categories shift in continuous phonetic hyperspace. Because of the feedforward organization of the grammar, however, representations at lower levels furnish the data for the construction and updating of representations at higher levels. During grammar transmission, therefore, information flows predominantly from lower to higher modules: the grammar is bootstrapped from the bottom up. Mirroring this process, historical innovations generally propagate from lower to higher modules:

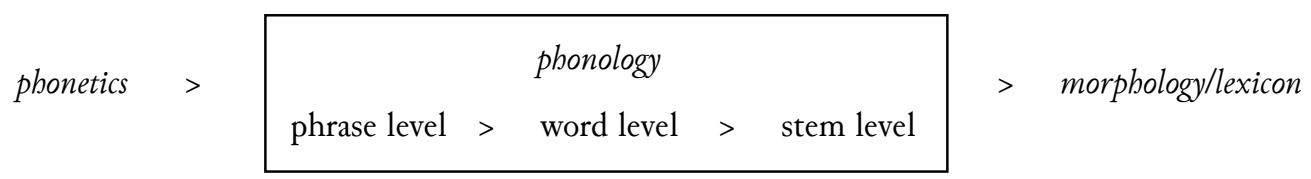

The main steps in the life cycle of phonological processes, and their causes in the mechanism of grammar transmission, are described in more detail in §2.3.

Since the balance between synchronic and diachronic explanation has become a major arena for the innateness controversy (see $§ 1$ ), I emphasize that neither of the predictions just outlined crucially requires that the modular feedforward architecture be available to the learner prior to all linguistic experience. For example, Bermúdez-Otero (2012: 31-40, 76) suggests ways 
in which elements of cyclicity and stratification may emerge during acquisition from the interaction of factors such as the schedule of the child's morphosyntactic development, lexical listing, and morphological blocking. Architectural explanations of properties of phonological change are perfectly compatible with such epigenetic approaches to the architecture itself, as long as the latter do not presuppose the diachronic facts to be explained.

\subsection{Neogrammarian change}

In the modular feedforward architecture, innovation in the phonetic component of the grammar manifests itself as neogrammarian change. Such change is phonetically gradient because it affects the real-valued attributes of the phonetic realizations assigned by languagespecific phonetic rules to surface phonological categories in specific environments. It is lexically regular insofar as the computation of phonetic targets is exhaustively determined by information present in, or derivable from, the surface phonological representation, and the latter does not contain diacritics of lexical or morphological affiliation: see the 'Phonetic Interpretability Hypothesis' of Bermúdez-Otero (2012: 81), and cf. below for putative counterevidence. By the same token, neogrammarian change is expected to be sensitive to surface prosodification, but not to underlying morphological structure.

Whether changes meeting this description actually exist has long been debated. Few challenge the existence of phonetically gradual innovation—although Wang (1969) did claim that most, if not all, sound changes were classically diffusing, i.e. lexically gradual but phonetically abrupt. However, there are contemporary phonological frameworks that cannot accommodate truly gradient change. On the basis of radically rationalist assumptions about language acquisition, Hale et al. (2006, this volume), e.g., assert that phonetic implementation is performed by innately specified articulatory and perceptual 'transducers' that refer to surface phonological representations consisting of features drawn from an inventory supplied by Universal Grammar. In this framework, the phonetic target for a particular feature in a particular environment remains fixed through time because it is innately specified by the transducers; only the discrete featural content of surface representations can change. Hale et al.'s theory thus entails that there cannot be continuous phonetic change stricto sensu; the illusion of gradience must arise from variation between competing grammars with categorically different outputs.

Fruehwald (2012) argues against this claim, using evidence from the raising of English /ai/ before voiceless obstruents in the dialect of Philadelphia during the twentieth century as attested in the Philadelphia Neighbourhood Corpus (PNC). Fruehwald simulated the gradient advance of this change by mixing tokens of two discrete allophones, categorically unraised [ar] and categorically raised [pi], and gradually increasing the proportion of [pi]-tokens over time. In this category-mixing scenario, the overall distribution of prevoiceless tokens of /aI/ on the F1 continuum exhibits high kurtosis near the start of the change, when most tokens belong to category $[\mathrm{ar}]$; the distribution also displays high kurtosis near the end of the change, when 
most tokens belong to category [ri]; but mid-way through the change kurtosis falls to a minimum because, at this point, /ai/ is realized by an even mixture of [ar]-tokens and [ri]tokens. ${ }^{1}$ The PNC data, however, do not conform to the predicted pattern: the distribution of prevoiceless /aI/-realizations shows the most normal-like kurtosis at the mid-point. This failure of kurtosis to fall and then rise again is particularly significant because, of all vowel changes attested in the PNC, /ar/-raising covers the longest acoustic distance in the shortest time, and should therefore exhibit the clearest dip in kurtosis. Fruehwald's results indicate that the raising of /ai/ before voiceless obstruents in Philadelphia did not involve competition between two categories; it was truly continuous.

The challenge most often levelled against the neogrammarians focuses on regularity rather than on gradience: it is often claimed that no change is fully lexically regular (Phillips, this volume). Labov (2010: ch. 13), however, shows that/u:/- and /ov/-fronting in North American English fit the neogrammarian description admirably. Allophones of /u:/, in particular, remain categorically back before $/ 1 /$, but other tokens of the vowel exhibit gradient fronting, forming a unimodal distribution on the F2 dimension. A word's position within this fronting continuum is exquisitely sensitive to the phonetic environment of the vowel, with preceding onsets forming a cline from favouring (e.g. coronals) to disfavouring (e.g. labials). Crucially, the lexical affiliation of /u:/-tokens is not a significant predictor of fronting: in a regression analysis, only affiliation to the words zoo and Vancouver reached significance at the $\mathrm{p}<.01$ level, and even then this effect could not be distinguished from the unique phonological properties of the two items (e.g. the combination of onset / $\mathrm{z} /$ and unchecked /u:/ in zoo); revealingly, both lexical effects disappeared when separately tested on two halves of the data. Just as importantly, the token frequency of words was not a significant predicting factor. Thus, the fronting of non-prelateral /u:/ in North American English is a canonical neogrammarian change: phonetically gradient and lexically regular.

Other studies do report continuous phonetic properties to be significantly affected by nonphonological factors such as lexical token frequency and neighbourhood density (see e.g. Munson and Solomon 2004, among many others). However, the actual scope of such wordspecific effects is unclear. Notably, Dinkin (2008) found evidence that high-frequency words do lead in reductive changes such as vowel centralization, but not in nonreductive changes such as the Northern Cities Shift—or indeed /u:/- and /ov/-fronting as described by Labov. Moreover, the evidence of lexical effects on phonetic variation often seems compatible with accounts that preserve the essential features of the modular feedforward architecture at Marr's computational level (see §2.1 above): for example, Baese-Berk and Goldrick (2008) propose a speaker-driven model of neighbourhood density effects that relies on cascading activation in production processing (though cf. Goldrick et al. 2011 for limitations).

\footnotetext{
1 Kurtosis can be thought of as a measure of unimodality (Darlington 1970). Thus, a bimodal mixture of two
} distributions exhibits low kurtosis. 
In contrast, pure exemplar-based models relying on the storage of fine phonetic detail in long-term memory predict the existence of word-specific phonetic effects, but have difficulty accounting for the evidence of neogrammarian change (Pierrehumbert 2002: 120); neogrammarian regularity has been thought to require some dissociation between lexical and phonetic knowledge at least since Bloomfield (1933: 364-5). However, exemplar theories come in many flavours, crucially differing in their ontology for phonological category labels and in the extent to which they acknowledge a role for classical symbolic computation in phonology (Bermúdez-Otero 2007: 512, 515). Exemplar theories in which storage is organized around phonological categories (e.g. Pierrehumbert 2002) enjoy far better prospects than those in which storage is organized around lexical units (e.g. Bybee 2001, this volume): see Sóskuthy (2011) for a comparison of 'category-based' and 'word-based' exemplar storage. Further questions arise if, as argued by Smolensky (2006), a comprehensive framework for understanding human cognition needs to establish lawful relationships between 'computational', 'algorithmic', and 'physical' descriptions (Marr's terms) that are nonetheless radically anisomorphic: in this vein, one wonders if the best category-driven exemplar model might turn out to be a low-level implementation of the best modular symbolic theory, and the best modular symbolic theory might prove to be a high-level approximation to the behaviour of the best category-driven exemplar model.

A third challenge to the existence of neogrammarian change as predicted by the modular feedforward architecture arises from the claim that phonetic implementation is directly sensitive to morphological structure (Kawahara 2011: §2.3.3). This possibility was already explicitly denied by Kruszewski (1881 [1995: 27]), and has since been ruled out in a wide range of theories, including Boersma (2009b), which assert that morphology and phonetics do not share an interface. In §2.4 I demonstrate that phonetic variation may exhibit morphological effects only in appearance, as a result of rule scattering during the life cycle of phonological processes.

\subsection{The life cycle, input restructuring, and rule scattering}

Diagram (4) represents the diachronic pathway along which linguistic sound patterns typically evolve over long periods of time (Bermúdez-Otero 2007: 504-5, Bermúdez-Otero and Trousdale 2012: §2, Ramsammy forthcoming). In the course of this life cycle, a phonetic phenomenon that is at first exhaustively determined by extragrammatical factors (physics and physiology) becomes ever more deeply embedded in the grammar of a language, first as a language-specific gradient process of phonetic implementation, later as a categorical phonological rule applying in increasingly narrow morphosyntactic domains, until it eventually escapes phonological control altogether. As noted by Bermúdez-Otero and Trousdale (2012: 693 et seq.), the life cycle bears an obvious resemblance to grammaticalization: it is, for example, overwhelmingly unidirectional, allowing at most an occasional retrograde step, always isolated (Kiparsky, this volume: note 11; and see below for an example). 
(4) The life cycle of phonological processes (Bermúdez-Otero and Trousdale 2012: 700)

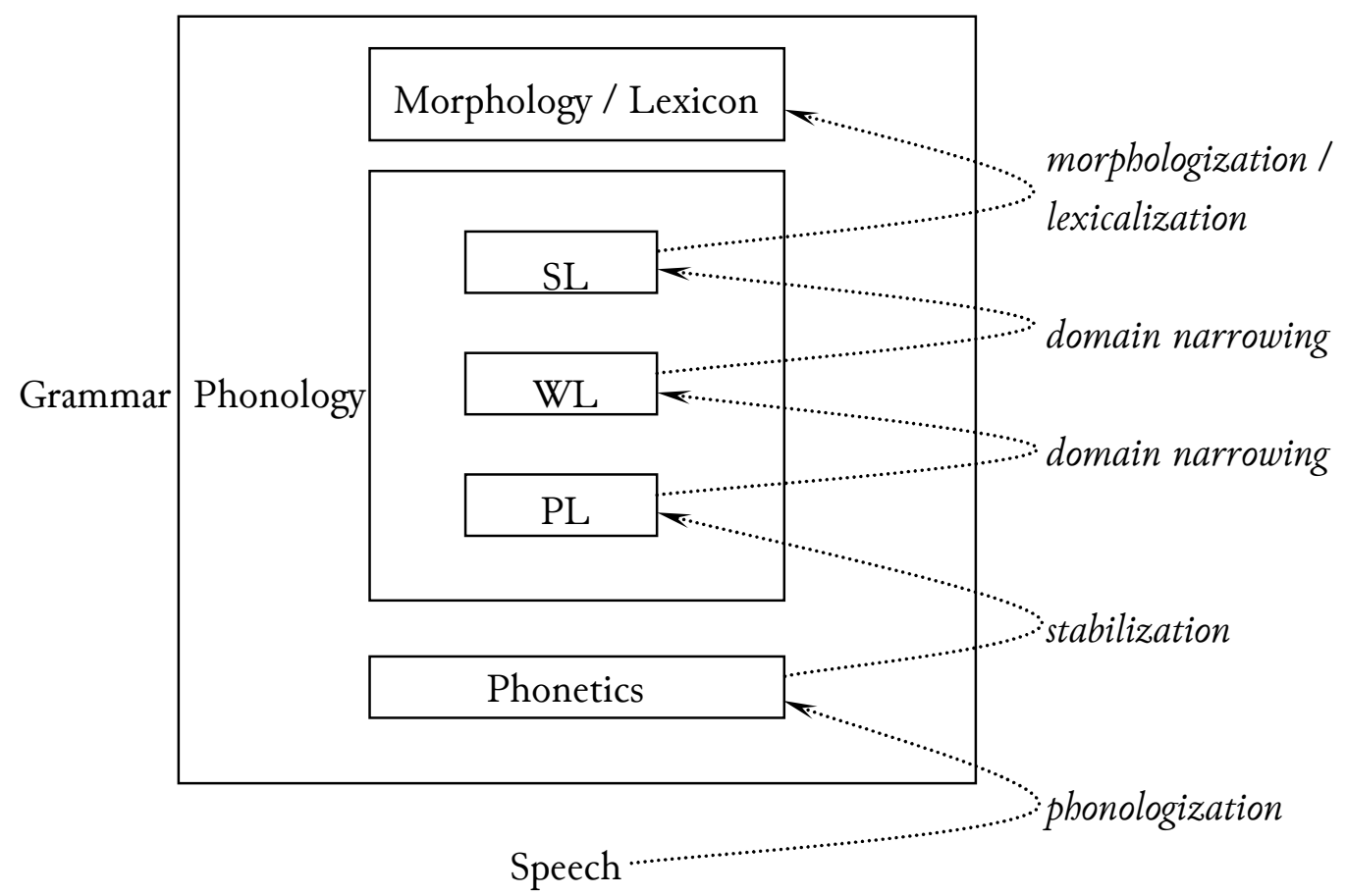

New sound patterns enter the grammar through phonologization (Hyman 1976;

Kiparsky, this volume). This occurs when a listener/learner misinterprets the effects of a purely physical or physiological phenomenon as being under the control of speakers' grammars, and so adjusts her phonetic implementation rules accordingly (Ohala's 1981 'hypocorrection'; also Yu, this volume). Empirically, phonologization becomes apparent through an increase of the effect beyond the magnitude warranted by extragrammatical causes; feedback and sociolinguistic incrementation (D'Arcy, this volume) may then amplify it further. Boersma (2009a) and Hamann (2009) provide a persuasive formal account of the role of perceptual factors and modular representations in this process, supported with computational simulations. Their model predicts the structure-preserving bias noted by Kiparsky (1995: 656), see BermúdezOtero and Trousdale (2012: 694).

Phonologization is conceptually and empirically different from stabilization. The latter takes place when some effect of a gradient process of phonetic implementation is reanalysed as being generated by a categorical phonological rule applying across the board in phrase-level domains; the circumstances that may lead to this development are discussed below. Recognizing stabilization requires empirical tests for distinguishing between gradient and categorical patterns (e.g. Myers 2000): Strycharczuk (2012: 45-47) provides particularly careful discussion. The available criteria have led to the identification of several instances of stabilization in progress within a speech community. Relying on a bimodality criterion, for example, Bermúdez-Otero and Trousdale (2012: 694) show, on the basis of articulatory data 
from Ellis and Hardcastle (2002), that external sandhi in English /n\#k/ clusters involves gradient reduction of the nasal's tongue-tip gesture in some idiolects, but categorical feature delinking and spreading in others. Using a speech-rate test, Strycharczuk (2012: ch. 6) identifies a similar state of affairs in Quito Spanish. In this variety of Spanish, some speakers have a variable phonological rule that categorically voices underlying /s/ in word-final position before sonorant segments (see Bermúdez-Otero 2011: $§ 6$ for derivations and their relevance to the architecture of phonology). In the phonetics, categorically voiced tokens of /s/ target a fixed ratio between the duration of the voiced interval and the overall duration of the consonant. Accordingly, speakers with categorically voiced /s/ actively prolong glottal pulsing at slow speech rates as the fricative becomes longer. For other speakers, however, the voicing of wordfinal /s/ before sonorants is coarticulatory: in these idiolects the ratio of voicing duration to overall consonant duration falls at slow speech rates.

After a sound pattern has become categorical, further changes may reduce its morphosyntactic domain, so that the rule ascends within the phonology from the phrase level to the word level, and from the word level to the stem level. Domain narrowing subsumes many cases of what the neogrammarians called 'analogical change', though by no means all. The evolution of postnasal / $\mathrm{g} /$-loss in Late Modern English provides a particularly beautiful example. This phonological process deletes underlying $/ \mathrm{g} /$ in the coda when immediately preceded by homorganic $/ \mathrm{n} /$. Thanks to a report from the eighteenth-century orthoepist James Elphinston (Garrett and Blevins 2009: 528), it is possible to reconstruct all the successive changes that the domain of this rule underwent between Early Modern English and the present day (Bermúdez-Otero 2011: 2024-5, Bermúdez-Otero and Trousdale 2012: §2.2).

(5) Domain narrowing in the history of postnasal /g/-deletion (Bermúdez-Otero 2011: 2024)

\begin{tabular}{|c|c|c|c|c|c|c|}
\hline Stage & $\begin{array}{l}\text { Realizat } \\
\text { elongate }\end{array}$ & $\begin{array}{l}\text { on of under } \\
\text { prolong-er }\end{array}$ & $\begin{array}{l}\text { lying /ng/ } \\
\text { prolong it }\end{array}$ & prolong \| & $\begin{array}{l}\text { Level reached } \\
\text { by the rule }\end{array}$ & Period or variety \\
\hline 0 & ng & $\mathrm{ng}$ & ng & $\mathrm{gg}$ & - & Early Modern English \\
\hline 1 & gg & $\mathrm{gg}$ & $\mathrm{gg}$ & g & phrase level & Elphinston (formal) \\
\hline 2 & gg & $\mathrm{gg}$ & $g$ & g & word level & Elphinston (casual) \\
\hline 3 & $\mathrm{gg}$ & $\mathrm{g}$ & $\mathrm{g}$ & $\mathrm{g}$ & stem level & present-day RP, GenAm \\
\hline
\end{tabular}

Below I describe a recent computational study by Lignos (2012) which casts light on the factors that drove this process of domain narrowing and determined its speed.

At the end of their life cycle, sound patterns come under increasing morphological and lexical control. For example, a stem-level phonological process may come to apply as a mere lexical redundancy rule (Jackendoff 1975) subject to blocking; such rules sustain exceptions and exhibit cyclic reapplication effects, which spread and retreat historically by lexical diffusion (see Bermúdez-Otero 2012: 34-39 and 74 for two case studies). Finally, a phonological process may be replaced by a morphological rule of exponence controlling the distribution of a morph 
(Anderson 1988: 329ff, and Fertig, this volume), or it may die altogether, leaving behind no more than inert traces in underlying representations.

Pace Hale et al. (this volume), one need not invoke 'mystical, pan-generational forces' to sustain this life cycle. Rather, as I anticipated in $\$ 2.1$, the explanation for its predominant unidirectional character lies in the mechanism of phonological innovation. In line with a widespread view, I assume that innovations originate in permanent replication errors during grammar acquisition and grammar updating, i.e. replication errors from which the affected individual does not recover-unlike consonant harmony and long word reduction in typically developing children (Foulkes and Vihman, this volume). Crucially, the organization of grammars causes certain permanent replication errors to occur far more frequently than conceivable alternatives. In particular, properties derived in a module or submodule are often misanalysed as being already present in its input, leading to the restructuring of input representations. The prevalence of this phenomenon reflects the fact that, whereas information flows downwards in production, it propagates generally upwards in grammar acquisition and updating. It is thus recurrent input restructuring, firmly rooted in mechanisms of grammar transmission, that imparts its direction to the life cycle of phonological processes.

Input restructuring can be clearly seen at work in the process of domain narrowing that lifted postnasal /g/-deletion from the phrase level to the word level. Consider an eighteenthcentury listener/learner who has acquired a transparent ban on coda $[\mathrm{g}]$ after [ $\mathrm{y}]$. To replicate Elphinston's phrase-level alternation between [sinll] and ['sin.gə.'laud], this individual needs to represent the verb sing as /sing/ in the input to the phrase level, so that the final $/ \mathrm{g} / \mathrm{may}$ be rescued by resyllabification when immediately followed by a vowel in the next word. In turn, this means that this listener/learner must model her word-level representation of sing on her experience of prevocalic tokens; but, crucially, the odds are stacked against her: preconsonantal and prepausal tokens outnumber prevocalic ones roughly by three to one. It is therefore not surprising that some individuals should have replaced conservative word-level/sing/ with innovative /sin/:

(6) Input restructuring during postnasal /g/-loss (Bermúdez-Otero and Trousdale 2012: 698) word-level output $=$ phrase-level input

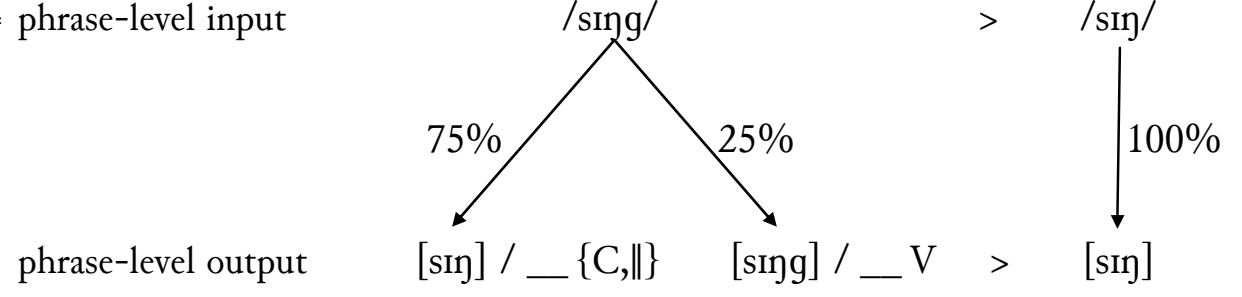

Thus, the likelihood of input restructuring, which sustains the life cycle, does not in the least depend on the ebb and flow of mystical forces, as Hale et al. (this volume) claim, but on quantitative properties of the data available to listeners/learners in particular situations. Indeed, hypotheses about the mechanism of input restructuring can be tested rigorously using computational simulations of learning. Take the striking fact that, in Late Modern English, 
coda-targeting processes that reach the word level through domain narrowing are never confined to that stratum for long, but continue climbing up into the stem level (BermúdezOtero and McMahon 2006: 401-2). This is in stark contrast with Dutch, where, for example, coda devoicing has remained stuck at the word level (Booij 1995: 22, 55-6, 174-5) for centuries, probably since the Old Low Franconian period. A plausible explanation for the divergent evolution of the two languages lies in the relatively impoverished inflectional system of English, which has retained fewer vowel-initial endings than Dutch and uses them less often. In consequence, stem-final consonants surface much more frequently as codas in English inflectional paradigms than in Dutch ones: compare, for example, English bood SG [hud] PL [hudz] with Dutch boed 'hat' SG [hut] PL [hu.dən].

To test this, Lignos (2012) simulated the acquisition of $[\mathrm{g}] \sim \varnothing]$ alternations across multiple generations, using Yang's (2005) productivity criterion to estimate the point at which a generation would have enough evidence to posit a rule of postnasal $/ \mathrm{g} /$-deletion at a particular level. Lignos found that the deletion process remained confined to the phrase level unless the rate of resyllabification across word boundaries fell below a certain threshold; adding plausible restrictions against /g/-resyllabification before liquids and before stressed vowels allowed domain narrowing to go through. Crucially, once postnasal/g/-deletion became active at the word level, its further ascent to the stem level encountered no resistance. Thus, Lignos's simulation supports the explanation proposed above for the greater vulnerability of word-level phonological rules to domain narrowing in English than in Dutch.

The pace at which phonological processes travel on their life cycle is thus closely dependent on the mechanisms of grammar transmission. As further evidence, consider the fact that unidirectionality has been found to break down in circumstances that favour higher rates of replication error than intergenerational transmission within a speech community: a notable case is the propagation of dialect features across communal groups through contact between adult speakers (Bermúdez-Otero and Trousdale 2012: §2.4). For example, Labov (2007: 369) shows that New York City short- $a$ tensing underwent domain broadening-as opposed to the usual domain narrowing - when borrowed into the dialect of New Orleans. Crucially, the vehicle for borrowing was the migration of New York bankers and merchants to New Orleans (Labov 2007: 367-8).

So far I have illustrated the role of input restructuring in the life cycle of phonological processes with examples of domain narrowing. Nonetheless, stabilization as described above also involves input restructuring, for it alters the inventory or distribution of categories in the surface phonological representations that provide the input to phonetic implementation. In this respect, an interesting possibility is that stabilization supervenes when outlying tokens of a surface category are perceived as manifestations of a different, possibly new, category. Consider a hypothetical scenario involving the realization of a surface vowel category in F1/F2 space (7). Initially, the tokens of this vowel category are evenly spread around the mean, creating an approximately globular distribution (7,a). However, a subset of the tokens (represented by black 
circles) occur in a phonetic environment that triggers gradient F2-lowering: within the overall distribution, therefore, these tokens gravitate towards the back of the vowel space. Suppose now that the magnitude of this conditioned F2-lowering effect increases historically through phonologization, possibly reinforced by feedback and sociolinguistically driven incrementation: as a result, the distribution becomes skewed, with some affected tokens lying far back of the overall mean $(7, b)$. In $(7, c)$, some outliers have been reanalysed as tokens of a new surface category; speakers for whom this happens develop an innovative phonological rule of conditioned backing that applies variably but categorically.

a. initial state

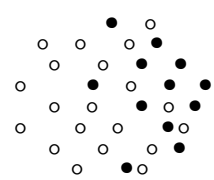

tokens in F2-lowering environment

tokens elsewhere b. phonologization

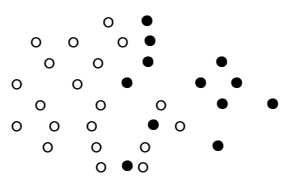

c. stabilization

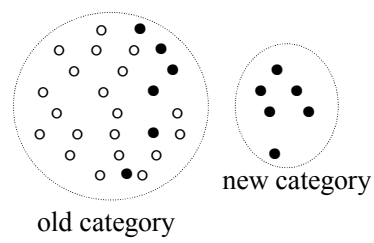

This scenario implies that the listener/learner's failure to compensate adequately for coarticulatory and reductive effects (Ohalian hypocorrection) plays a key role not only in phonologization (above) but also in stabilization. The idea that distributional skews play an instrumental role in stabilization receives support from experiments on infant perception: Maye et al. (2002) showed that infants familiarized with a continuum of speech sounds learn to discriminate tokens from the endpoints of the continuum if the latter is bimodally distributed, but not if it is unimodal. More generally, scenario (7) implies that listeners/learners set up surface phonological categories largely by bottom-up means (Strycharczuk 2012: 15, 164-5, 176), rather than through procedures narrowly constrained by top-down supervision (cf. the contrastivist principle in Dresher and Zhang 2005: 55). Baker et al. (2011) propose a somewhat similar account of stabilization in which outlying tokens also play a key role, but their model additionally emphasizes sociolinguistic heterogeneity within the speech community. Admittedly, these scenarios remain programmatic suggestions: detailed computational simulations are needed to verify the extent to which their predictions actually follow from their premises, and perceptual experiments with children and adults are needed to test the role of both distributional skews and sociolinguistic heterogeneity in phonological category formation. More worryingly, we have at present no good account of how learners assign featural labels to the categories they establish in surface phonological representations (Boersma 2012: §9.3.7).

Nonetheless, an appealing feature of scenario (7) is that, without further stipulation, it predicts the fact that stabilization is normally accompanied by rule scattering: in other words, the original gradient process of phonetic implementation remains active in the grammar even after the new categorical rule enters the phonology (Bermúdez-Otero 2007: 506; 2010). Observe 
that in $(7, c)$ vowel tokens in the backing environment are split between the old and the new category. Within the former, it remains the case that tokens in the backing environment exhibit lower than average F2. The overall pattern, therefore, supports the acquisition of two generalizations: an optional rule of categorical backing, overlaid with a gradient process of F2lowering.

Rule scattering is robustly attested in English phonology (Bermúdez-Otero 2007: 506). For example, Labov (1994) demonstrates that an accurate description of Philadelphia short- $a$ tensing requires two separate statements in the grammar: a stem-level phonological rule that applies in lexical redundancy mode and captures the default distribution of lax $/ \mathfrak{x} /$ and tense $/ x: /$ and a gradient phonetic rule that controls the precise location of / $x: /-$ tokens in F1/F2 space. Two facts confirm that $/ \mathfrak{x} /$ and $/ \mathfrak{x}: /$ are discrete categories in the dialect of Philadelphia: the two vowels occupy largely nonoverlapping regions in acoustic space (Labov 1989: 8-10), and their occurrence is not fully predictable - as notably shown by the contrast between $/ \mathfrak{x}: /$ in mad, bad, glad and /x/ in sad, fad, lad. Trends in the distribution of / $/$ and / $/$ : are captured by a default rule that takes the stem as its domain (Labov 2010: 260) and so is rendered opaque by the addition of word-level suffixes (see Bermúdez-Otero 2007: 509-10 for an implementation in Stratal OT); within this stem-level domain, the main generalization is that the vowel is tense before coda $/ \mathrm{m}, \mathrm{n}, \mathrm{f}, \theta$, s/. In the phonetics, the precise formant values of $/ \mathfrak{x}$ /-tokens are exquisitely sensitive to their environment: salient effects include a sizeable amount of F1-lowering in tokens followed by a nasal, and a smaller amount in tokens preceded by a nasal. Similar effects are found in the Inland North, where short- $a$ realizations form a single category subject to neogrammarian raising and fronting. The crucial observation is that, in Philadelphia, the stem-level default rule controlling the distribution of $/ \mathfrak{x}: /$ and the gradient process determining its acoustic realization both refer to very similar factors (e.g. coda nasals). This ultimately reflects the fact that both generalizations have similar phonetic grounds; it is just that the stem-level process has distanced itself further from its phonetic origins over centuries of complex history, starting with an allophonic rule that lengthened short /a/ in Early Modern English (Labov 1989: §2).

\subsection{Morphology-free phonetics: the case of English /1/-darkening}

Rule scattering can create the appearance of morphologically sensitive phonetics without actually violating the restrictions of the modular feedforward architecture. I illustrate this with one of Kawahara's (2011: 2290-1) putative examples of morphologically conditioned phonetic implementation: English /1/-darkening.

Sproat and Fujimura (1993) show that, articulatorily, darkening causes the gesture of tongue-dorsum retraction for $/ 1 /$ to increase in magnitude and to reach its peak earlier relative to tongue-tip raising: 
(8) Gestural scores for English /l/ (Sproat and Fujimura 1993: 307)

a. dark

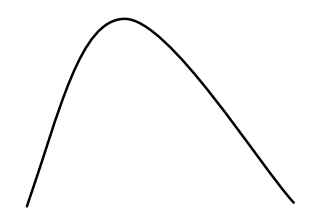

apical gesture

dorsal gesture

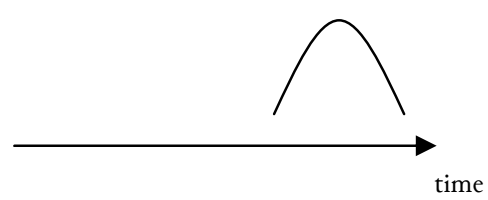

b. light

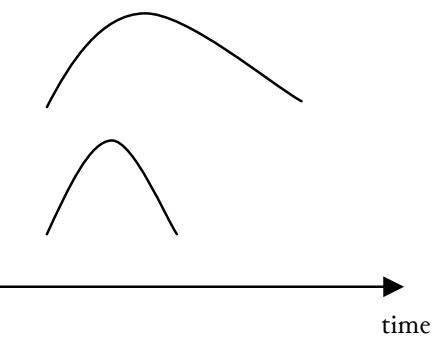

In addition, Sproat and Fujimura observe that, in a sequence of vowel plus [1], the relative delay of the apical gesture for [ 1$]$ increases continuously in proportion to the overall duration of the sequence. They conclude that /1/-darkening is a purely gradient process of phonetic implementation.

At the same time, evidence shows that /1/-darkening is morphologically conditioned. Hayes (2000) asked ten native speakers of American English to rate the well-formedness of light and dark /1/ in various morphologically defined environments; Boersma and Hayes (2001: $76,82)$ then used a sigmoid transformation to convert these well-formedness judgements into estimated frequencies of [1] and [1]. The results show a strong morphological effect: notably, the estimated frequency of light [1] is much lower stem-finally in complex words like bail-y than morpheme-medially in simple words like Hayley.

(9) Estimated frequency of light [1] (Boersma and Hayes 2001: 76)
a. light
b. Louanne
99.923
c. gray-ling, gai-ly, free-ly
94.53
d. Mailer, Hayley, Greeley, Daley
76.69
e. mail-er, hail-y, gale-y, feel-y
f. mail it
g. bell, help
0.0011

$\frac{\%}{99.956}$

This morphological effect is not mediated by prosodic structure (Bermúdez-Otero 2011: §4).

The modular feedforward architecture does not allow continuous processes of phonetic implementation to refer directly to morphological structure. If Sproat and Fujimura were right that $/ 1 /$-darkening is purely gradient, then this phenomenon would disprove the modular feedforward architecture. However, Hayes (2000: 93) and Bermúdez-Otero (2007: 516) reject their claim, and suggest that /1/-darkening involves two separate generalizations coexisting synchronically in the grammar: a morphologically sensitive phonological rule that creates 
discrete light and dark allophones, and a gradient phonetic process that adjusts the gestural score of $[\mathrm{f}]$ according to duration. In this scenario, only the categorical phonological rule shows morphological conditioning; the constraints of the modular feedforward architecture are therefore satisfied. Bermúdez-Otero (2007: 516) and Bermúdez-Otero and Trousdale (2012: $705)$ portray this state of affairs as the natural outcome of the diachronic mechanism of rule scattering described in $§ 2.3$.

Yuan and Liberman $(2009,2011)$ provide conclusive evidence against the claim that $/ 1 /$ darkening is purely gradient. Using forced alignment to analyse a corpus of utterances by the Justices of the United States Supreme Court, they labelled /1/-tokens in canonical onset position (e.g. like, please) as light, and /1/-tokens in canonical coda position (e.g. full capacity, $f e l t$ ) as dark. From this they derived a continuous measure of darkness, the ' $D$ score', such that darker tokens of $/ 1 /$ had larger $D$ scores. As predicted by Sproat and Fujimura, Yuan and Liberman found that the $D$ score of non-foot-initial /1/ was positively correlated with the duration of the vowel+/1/ string. Contrary to Sproat and Fujimura's claims, however, non-footinitial tokens of $/ 1 /$ turned out to have positive $D$ scores even when they belonged to very short vowel+/1/ sequences. Similarly, foot-initial /1/ always had a negative $D$ score, on which duration had no effect. Thus, fully in line with a rule scattering scenario, Yuan and Liberman's findings confirm that English has a categorical distinction between light [1] and dark [ 1 , overlaid with gradient duration-driven adjustments of gestural phasing in the realization of dark [ $\mathrm{t}]$.

One can detect diachronic rule scattering not only in the synchronic coexistence of a gradient and a categorical version of /1/-darkening, but also in the morphological effects displayed by latter. Reanalysing Boersma and Hayes's data using Stochastic Stratal OT, Turton (2012) observes that the probability of darkening grows in proportion to the number of cycles in which / $1 /$ is syllabified in coda position:

\begin{tabular}{|l|l|l|l|l|l|l|l|}
\hline \hline \multirow{2}{*}{ form } & \multicolumn{6}{|l|}{$/$ / not foot-initial? } & \multicolumn{2}{l|}{ // in coda? } & \multirow{2}{*}{ \% of dark [1] } \\
\cline { 2 - 7 } & $\begin{array}{l}\text { stem } \\
\text { level }\end{array}$ & $\begin{array}{l}\text { word } \\
\text { level }\end{array}$ & $\begin{array}{l}\text { phrase } \\
\text { level }\end{array}$ & $\begin{array}{l}\text { stem } \\
\text { level }\end{array}$ & $\begin{array}{l}\text { word } \\
\text { level }\end{array}$ & $\begin{array}{l}\text { phrase } \\
\text { level }\end{array}$ & \\
\hline \hline Hayley & $\checkmark$ & $\checkmark$ & $\checkmark$ & & & & 23.31 \\
\hline mail-er & $\checkmark$ & $\checkmark$ & $\checkmark$ & $\checkmark$ & & & 83.33 \\
\hline mail it & $\checkmark$ & $\checkmark$ & $\checkmark$ & $\checkmark$ & $\checkmark$ & & 99.51 \\
\hline bell $\|$ & $\checkmark$ & $\checkmark$ & $\checkmark$ & $\checkmark$ & $\checkmark$ & $\checkmark$ & 99.9989 \\
\hline \hline
\end{tabular}

In American English, therefore, the phonological process that darkens /1/ in codas applies variably at the stem, word, and phrase levels. ${ }^{2}$ Therefore, rule scattering did not stop with

\footnotetext{
2 Alongside coda-based darkening, a general process applies variably to $/ 1 /$ in non-foot-initial positions, including foot-medial onsets, shown by dark [ $\mathrm{t}$ in forms like Hayley $(9, \mathrm{~d})$, where /1/ stays in the onset throughout
} 
stabilization: after splitting into a gradient process of phonetic implementation and a discrete phonological rule, /1/-darkening went on to undergo two rounds of domain narrowing, ascending to the word and stem levels while remaining active in lower strata.

The pattern in (10) provides a striking quantitative illustration of a key prediction of stratified phonological theories: opacity at a stem-suffix boundary, as in the retention of darkened [1] before a vowel-initial suffix in mail-er, entails at least the same amount of opacity across word boundaries, as in mail it. This follows from the Russian Doll Theorem (BermúdezOtero 2011: 2023-4, Ramsammy 2012). The quantitative signature of stratification was first noted in Guy's (1991b, a) Lexical Phonology analysis of English /t,d/-deletion. Turton (2012) develops this in two ways, providing a method for calculating precise application rates at each phonological level, and showing how these rates emerge from the life cycle of phonological processes. According to (10), for example, the difference in the amount of darkening between mail-er and mail it corresponds to one application of coda-based darkening at the word level in mail it. Extending this line of reasoning to the totality of Boersma and Hayes's data, Turton (2012: 21) deduces the following darkening probabilities for coda /1/:

$\begin{array}{lll}\text { (11) } & \text { stem level } & 0.78 \\ \text { word level } & 0.97 \\ \text { phrase level } & 0.97\end{array}$

Coda-based darkening turns out to be nearly obligatory at the phrase and word levels, but to apply at a considerably lower rate at the stem level. Turton notes that, given the life cycle of phonological processes, this result is expected: the stem-level rate of $/ 1 /$-darkening is lower, because the rule reached the stem level by domain narrowing late in its life cycle, only after it had already become active at the phrase and word levels. Thus, diachronic rule scattering in a modular stratified architecture explains not only the synchronic coexistence of phonetic gradience and morphological conditioning, but also the relative size of morphological effects across environments.

More generally, the prevalence of rule scattering leads one to expect that languages will often contain multiple clones of the same process applying simultaneously in different grammatical components, each referring to the type of information and operating on the type of representation determined by its place in the grammar. This expectation is fulfilled. Erker (2012) shows, for example, that the variety of Spanish spoken by New Yorkers of Hispanic origin has two separate processes of reduction applying to /s/ in the coda: one deletes /s/ categorically; the other gradiently reduces the duration of the fricative interval. The morphemic status of /s/, i.e. whether it realizes an inflectional suffix or not, plays a role, but as predicted by the modular architecture it conditions categorical $[s]$-absence, whilst it has no effect on the generalization (§3.1). 
continuous dimension of fricative interval duration. Similarly, MacKenzie (2013) demonstrates that variable auxiliary contraction in English has two sources: allomorph selection in the morphology, and segmental reduction in the phonology. Significantly, each auxiliary exhibits a specific rate of insertion of its short allomorph; but the segmental reduction processes applying in the phonology, notably / $\mathrm{h} /$-deletion, are lexically regular. Particularly spectacular instances of rule scattering have been found in popular Brazilian Portuguese: Guy (1996) shows that, in this language, the presence or absence of final sibilant fricatives reflects cognate variable processes in the syntax (variable agreement), the morphology (variable allomorphy), and the phonology (variable sibilant deletion), the latter in turn probably arising from a gradient phonetic process of gestural reduction.

Not all apparent morphological conditioning in phonetics involves rule scattering (cf. Bermúdez-Otero 2010: §9-§21). Many cases submit to standard prosodic analyses. Others may require processing accounts, perhaps involving cascading activation: possible candidates include the effects reported by Cho (2001) and by Sebregts and Strycharczuk (2012). Time will tell if, after we try these explanations, a recalcitrant residue will remain. In the current state of knowledge, claims that morphology-phonetics interactions falsify the modular feedforward architecture of grammar are decidedly premature.

Finally, it might be objected that rule scattering involves extensive stipulation and rampant redundancy in synchronic grammars. In American English, for example, the conditions on /1/-darkening have to be stated four times: once in the phonetics (referring to duration), and three times in the phonology (referring to suprasegmental structure, and specifying different application rates at the phrase, word, and stem levels). This objection is true, but has no force. There is no good reason to expect that grammars should be individually elegant; they are the contingent products of protracted tinkering by biological and cultural evolution. As in any field, beauty is to be sought only in our global understanding of phenomena, reduced to order by a powerful theory with rich deductive structure. The way the architecture of grammar predicts the life cycle of phonological processes, and in which the life cycle in turn predicts complex synchronic outcomes that might otherwise be thought to challenge the architecture, provides all the elegance that one can legitimately hope for.

\section{Synchronic patterns created by the life cycle}

In amphichronic phonology, synchronic and diachronic explanation feed each other: in $§ 2$, we saw that the synchronic architecture of grammar determines the ways in which change may be implemented and lays down the track for the life cycle of sound patterns, while the diachronic operation of the life cycle accounts for the existence of scattered generalizations in synchronic grammars. In this section I shall provide two further examples of synchronic phenomena that emerge directly from the life cycle.

Bermúdez-Otero and Trousdale (2012: 699) compare the life cycle with an escalator that continuously lifts sound patterns from lower to higher components of the grammar. This 
analogy is by no means perfect: ordinary escalators move at a uniform pace, whereas in $\$ 2.3$ we saw that the speed with which individual phonetic and phonological processes rise through the grammar is contingent on the data available to listeners/learners and on the circumstances of grammar transmission. Nonetheless, the image of the escalator brings out a general prediction of the life cycle: one expects to find a partial but significant correlation between the relative ages of rules and their positions in the grammar. This correlation should manifest itself most clearly in cases where, by successive rounds of phonologization and stabilization, a series of categorical rules enter the phonological module in a recognizable sequence: in such cases, the older phonological rules, which suffer the longest exposure to the factors driving domain narrowing, will tend to apply in smaller cyclic domains than the younger rules.

Below I discuss two types of diachronic pathway that involve sequences of historical innovations following each other in nonrandom order: rule generalization scenarios and lenition trajectories. As predicted, older phonological rules typically end up applying in higher strata than younger counterparts. The resulting synchronic grammars instantiate certain typological tendencies in the stratal affiliation of phonological processes; however, these are epiphenomena of the life cycle and do not require synchronic explanation.

\subsection{Rule generalization and the life cycle}

Sound change often begins in specific environments where phonetic conditions are highly favourable, and progressively spreads to more general contexts. Schuchardt (1885: 22) described this as the innere Erweiterung der Lautgesetze '[the] internal expansion of the sound laws', which he contentiously regarded as caused by 'phonetic analogy', a label still used today. The term I use, 'rule generalization', gained currency in early generative phonology (Vennemann 1972: 1867; also Kiparsky 1988: §14.3.1).

The causes of rule generalization are imperfectly understood, but an adequate theory of phonologization and stabilization should account for generalization patterns just as it must predict the existence of rule scattering: see $\S 2.3$ above. Rule generalization is plausibly ultimately rooted in the scalar nature of the physical and physiological effects that initiate sound change. Feedback effects in grammar transmission and sociolinguistic incrementation probably play roles too. Moreover, we have reason to assume the involvement of top-down formal biases favouring relatively simple coarse-grained statements (Hayes 1999, Pater and Moreton 2012), for phonological rules typically distance themselves from their phonetic grounding as their environments become generalized (e.g. Strycharczuk 2012: ch. 5).

The Old High German consonant shift provides a case of rule generalization (also Ramsammy forthcoming). The Germanic voiceless plosives / $\mathrm{p}, \mathrm{t}, \mathrm{k} / \mathrm{affricate}$, and subsequently in certain cases spirantize. The change first targeted intervocalic plosives immediately preceded by short stressed vowels, and its environment then went on to expand in several steps, eventually including word-initial positions. For the labial /p/, Davis (2008: 212) reconstructs the progress as follows: 
(12)

\begin{tabular}{|c|c|c|c|c|c|c|}
\hline & $V_{\perp} V$ & ' $\left.V_{\ldots} \ldots\right]$ & ' $\overline{\mathrm{V}}$ & $\mathrm{IC}^{[+ \text {son }]}$ & 'VC_V V & {$\left[\omega^{\prime} \_V\right.$} \\
\hline stage 1 & $\checkmark$ & & & & & \\
\hline stage 2 & $\checkmark$ & $\checkmark$ & & & & \\
\hline stage 3 & $\checkmark$ & $\checkmark$ & $\checkmark$ & & & \\
\hline stage 4 & $\checkmark$ & $\checkmark$ & $\checkmark$ & $\checkmark$ & & \\
\hline stage 5 & $\checkmark$ & $\checkmark$ & $\checkmark$ & $\checkmark$ & $\checkmark$ & \\
\hline \multirow[t]{3}{*}{ stage 6} & $\checkmark$ & $\checkmark$ & $\checkmark$ & $\checkmark$ & $\checkmark$ & $\checkmark$ \\
\hline & opfan & gripf & släpfan & dorpf & scepphen & pflëgan \\
\hline & 'open' & 'grasp' & 'sleep' & 'village' & 'create' & 'care for' \\
\hline
\end{tabular}

The synchronic outcomes strikingly illustrate the way in which dialect geography can reflect the historical progress of rule generalization: Schuchardt (1885: 22) referred to this as die räumliche Projection zeitlicher Unterschiede 'the spatial projection of temporal differences'. This connection between rule generalization and geographical space arises because sound change originates in a focal area (Hock 1991: 440), from which it propagates outwards in line with Schmidt's (1872) wave theory. A change is therefore active for the longest time in its focal area and there eventually reaches its most general form by rule generalization. In the outermost areas, in contrast, the change may never progress beyond its initial, most narrowly defined environment. In the Old High German shift, the focal area lay south, in the Alemannic region, where the change reached its most advanced instantiation. As one moves northwards away from this focal area, one crosses isoglosses such as the Speyer line: to the south of this line, geminate plosives have undergone affrication (e.g. Apfel 'apple'); to the north, they remain unshifted (e.g. Appel). The utmost geographical reach of the Old High German shift is marked by the maken machen isogloss, the 'Benrath line'. Not far from this line lies the town of Wermelskirchen, whose Rhenish dialect exhibits consistently spirantized plosives only in the original environment of the shift after short stressed vowels (Iverson and Salmons 2006). Simplifying a great deal, therefore, the geographical signature of rule generalization shown in (12) could be represented graphically as follows: 
a. Stages $1-3 \quad$ b. Stages $4-5$

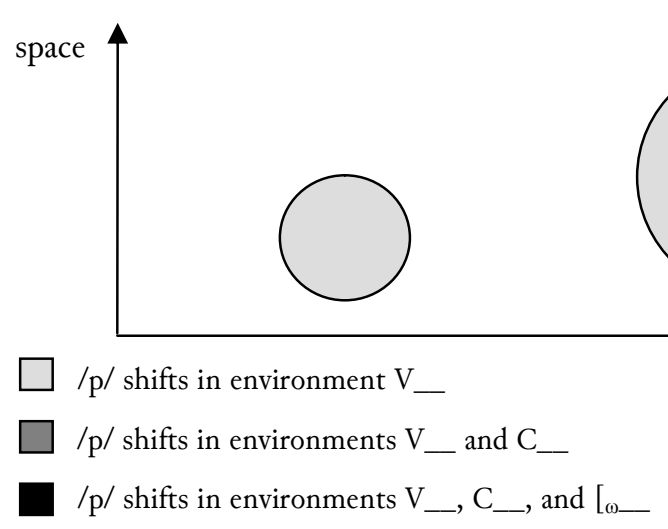

c. Stage 6
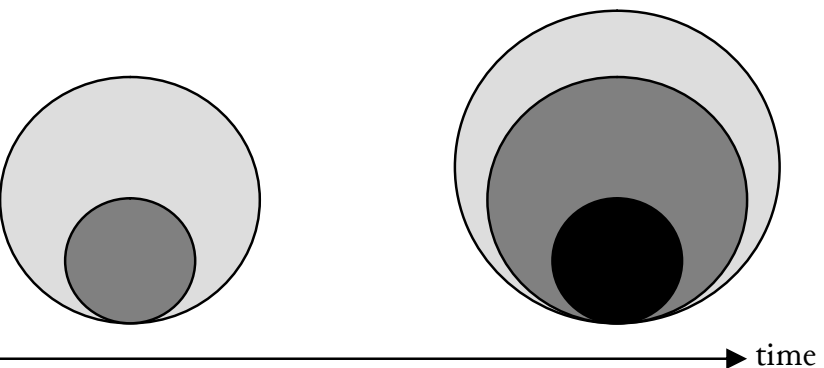

Late Modern English provides another example of rule generalization whereby the environment of two phonological rules, / $\mathrm{x} /$-deletion in nonrhotic dialects and /1/-darkening, has expanded along parallel prosodic tracks. In conservative dialects, these rules only target weak positions in the syllable, i.e. codas. In more advanced dialects, the processes apply in all weak positions within the foot, everywhere outside foot-initial onsets (Bermúdez-Otero 2011: 2039, and note 2 above). This is an instance of generalization insofar as the set of weak positions in the syllable is a proper subset of the set of weak positions in the foot. In (14) /1/darkening illustrates the typical implementation of rule generalization in OT: some constraint, here ${ }^{*}$, undergoes stepwise demotion relative to a markedness scale made up of constraints in a Paninian relationship, here ${ }^{*} 1 / \mathrm{Rh} \gg{ }^{*} 1 /\left[\mathrm{Ft} \ldots \mathrm{V}^{\prime} \ldots \ldots \ldots . . .\right.$.

\section{a. Rule-based implementation}
(1) $\quad 1 \rightarrow 1 / \stackrel{\mathrm{Rh}}{\mid}$
(2) $\quad 1 \rightarrow 1 /\left[\mathrm{Ft} \ldots \mathrm{V}^{\prime} \ldots \ldots \ldots\right]$
(specific)
(general)

b. Constraint-based implementation

$$
\begin{array}{lll}
\text { (1) } & * 1 / \mathrm{Rh} \gg{ }^{*} \mathrm{l} \gg{ }^{*} \mathrm{l} /\left[\mathrm{Ft} \ldots \mathrm{V}^{\prime} \ldots \ldots \ldots\right] & \text { (specific) } \\
\text { (2) } & * 1 / \mathrm{Rh} \gg{ }^{*} \mathrm{l} /[\mathrm{Ft} \ldots \mathrm{V} \ldots \ldots \ldots] \gg{ }^{*} \mathrm{f} & \text { (general) }
\end{array}
$$

Now consider how rule generalization interacts with the life cycle of sound patterns. The key point is that each step in a diachronic trajectory of rule generalization introduces a new phonological process into the grammar. Characteristically, this new process applies in a more general environment than its immediate precursor. Through phonologization and stabilization, the new rule ascends to the phrase level, and there becomes exposed to the mechanisms of input restructuring that drive domain narrowing (§2.3). This predicts that, in a trajectory of rule generalization, an older rule subject to relatively specific phonological conditions can come to apply in a higher stratum than a younger, more general successor, simply because the older rule became exposed to domain narrowing earlier in historical time. 
The history of $o$-lowering in Swiss German provides a clear instance. Robinson (1976) demonstrated that Swiss German dialects had undergone two waves of innovation causing $o$ to be lowered to $s$ : the first wave introduced a relatively specific rule applying before $r$ only; this was later followed by a more general process applying before all coronal consonants except $n$ and $l$. In (15) I provide rewrite-rule statements based on Robinson's: observe that the structural description of pre-r o-lowering is properly included within that of general $o$-lowering.

a. pre-r o-lowering

$$
\left[\begin{array}{c}
\mathrm{V} \\
\text {-high } \\
+ \text { back }
\end{array}\right] \rightarrow[+ \text { low }] / \stackrel{\sim}{-}\left[\begin{array}{c}
+ \text { son } \\
+ \text { cor } \\
- \text { nas } \\
- \text { lat }
\end{array}\right] \quad \text { i.e. } \quad \breve{o} \rightarrow \breve{s} / r
$$

b. general o-lowering

$$
\left[\begin{array}{c}
\mathrm{V} \\
\text {-high } \\
+ \text { back }
\end{array}\right] \rightarrow[+ \text { low }] / \stackrel{\mu}{\mid \mu}\left[\begin{array}{c}
+ \text { cor } \\
- \text { nas } \\
- \text { lat }
\end{array}\right] \quad \text { i.e. } \quad \breve{o} \rightarrow \breve{s} /\{r, t, d, \ldots\}
$$

Each of the two $o$-lowering rules went through its life cycle separately from the other, and, crucially, we can ascertain its morphosyntactic domain of application in any given dialect by analysing its interactions with regular umlaut (also Ramsammy forthcoming). Regular umlaut applies at the word level, where it is triggered by certain productive morphological operations such as zero plural inflection, the formation of diminutives in -li, etc. (see Kiparsky, this volume): I assume that the relevant suffixes introduce a floating [-back] autosegment that docks onto the stem vowel during the word-level phonological cycle. The key observation is that lowering does not apply to umlauted vowels, since these bear the feature [-back], and umlaut in turn does not alter the height of input vowels: i.e. $o$ in the input to the word level becomes $[\varnothing]$ when umlauted, whilst $\lrcorner$ becomes [œ]. Thus, umlauting of underlying /o/ yields surface [œ] only if $/ \mathrm{o} /$ is lowered to $\lrcorner$ already at the stem level. It is thus easy to provide a stratal analysis of the five stages in the history of Swiss German o-lowering that Robinson (1976: 151) reconstructed on the basis of dialect geography:

$$
\text { 'thorn' 'thorns' 'floor' 'floors' }
$$

Stage I

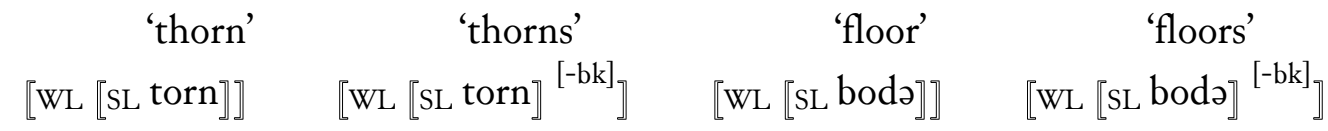

SL

WL umlaut

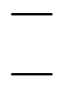

tørn

-

bødə

Surface

torn

tørn

bodə

bødə 


\section{Stage II}

SL

WL umlaut

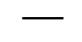

pre- $r$ lowering

Surface

$$
\text { tørn }
$$

tørn

torn

tœrn

tœrn

torn
SL pre-r lowering torn

WL umlaut

Surface

Stage IV (Schaffhausen)

SL pre- $r$ lowering torn

WL umlaut

general lowering (vacuous)

Surface

torn

\section{Stage V (Kesswil)}

SL general lowering ${ }^{1}$ torn

WL umlaut

Surface

torn

${ }^{1}$ Subsuming pre- $r$ lowering.

torn

tœrn

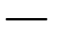

tœrn

torn

tœrn

tœrn

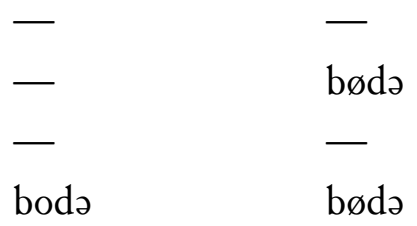

bødə 
favour of systems that obey statement (17): this generalization holds simply by virtue of the diachronic interaction between rule generalization and the life cycle of phonological processes.

\subsection{Lenition pathways and the life cycle}

Like a rule generalization scenario, a lenition trajectory also causes new phonological processes to enter the grammar in a recognizable sequence: in lenition trajectories, mild reductions precede more severe ones. No law dictates that, once a consonant has undergone some sort of weakening, it must stay on the same diachronic path to $\varnothing$ (cf. Vennemann's famous definition of lenition, recorded in Hyman 1975: 165). But in many cases, it is logically impossible to reorder the steps in a lenition cline. Consider a scenario where [s] is lost through an intermediate stage of debuccalization:

$$
\mathrm{s} \quad>_{\text {debuccalization }} \mathrm{h} \quad>_{\text {deletion }} \varnothing
$$

Clearly, $[\mathrm{s}$ ] can be lost without previously becoming [h], but it certainly cannot become $[\mathrm{h}]$ by disappearing first.

Honeybone (2008) surveys the history of thought about lenition. One question concerns the extent to which diachronic lenition pathways should be mirrored by scales in synchronic theory. Some lenition trajectories bear striking similarities to the sonority hierarchy thought to govern syllabification: e.g. $[\mathrm{t}]>[\mathrm{d}]>[\mathrm{r}]>\varnothing$, or $[\mathrm{t}]>[\mathrm{d}]>[ð]>[\mathrm{j}]>\varnothing$ (see the well-known diagram in Hock 1991: 83). In other cases, lenition correlates fairly directly with segmental complexity as determined by the presence or absence of certain features: e.g. [s] > $[\mathrm{h}]>\varnothing$, or $[\mathrm{t}]>[$ ? $]>\varnothing$.

For our purposes, the crucial observation is that synchronic grammars often contain separate phonological rules that reflect consecutive steps in a diachronic cline of lenition. When that happens, the older rules, reflecting milder forms of weakening, typically apply in narrower cyclic domains than the younger rules, which effect more drastic reductions. This is precisely the state of affairs predicted by the life cycle. Bermúdez-Otero (2011: 2034-7) discusses the example of $/ \mathrm{d} /$ in English nonrhotic dialects: $/ \mathrm{x} /$ undergoes reduction to $[\mathrm{I}]$ in the coda at the word level, as shown by the opaque overapplication of the process in word-final position before a word beginning with a vowel; full deletion, in contrast, operates at the phrase level, and so is transparent. Bermúdez-Otero and Trousdale (2012: 702-4) note that, in many English dialects, /1/ goes through the same type of synchronic derivation: it darkens in the coda at the word level, and vocalizes at the phrase level. 


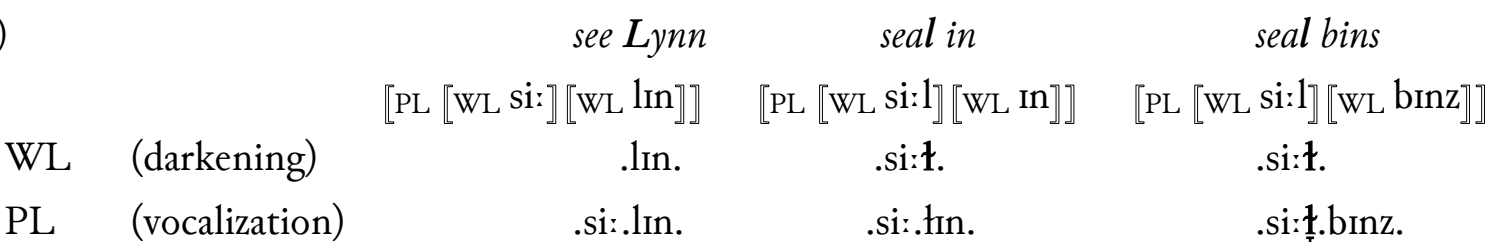

This pattern of stratal affiliation for lenition processes is in fact quite pervasive: Broś (2012: ch. 4) reports that, in a dialect of Spanish spoken in northern Chile, coda /s/ debuccalizes to [h] at the word level, and deletes categorically at the phrase level.

In phonological frameworks that endow lenition scales with synchronic status, either directly or indirectly, the examples reviewed could be regarded as instances of the following typological generalization:

(20) If two distinct processes of lenition within the same grammar target the same consonant in the same phonological environment but one causes greater weakening than the other, then the more drastic process is likely to have a wider cyclic domain.

As in the case of (17), however, there is no need to add this statement to our synchronic theory: (20) holds simply by virtue of the diachronic interaction between lenition trajectories and the life cycle of phonological processes.

\section{The irrelevance of Ockham's razor}

There is no simple methodological prescription for balancing synchronic and diachronic explanation. Certainly, one cannot pursue purely synchronic accounts of 'what is out there', trusting that historical change will do no more that shift languages from one permissible state to another within the grammar space defined by synchronic theory. As we saw in $\S 3$, 'what is out there' can be nontrivially moulded by diachronic processes in the first place. Conversely, diachronic explanation enjoys no epistemological priority over synchronic explanation: any attempt to justify such priority by appeal to Ockham's razor must fail, for the verdict of Ockham's razor is compelling only when one compares two empirically equivalent theories; but in any reasonably developed field of enquiry substantively different theories are hardly ever empirically equivalent, and so serious questions are settled not by Ockham's razor but by observation and experiment. The evidence in $\S 2$ indicates that, in fact, the architecture of grammar provides an indispensable element in the explanation of key properties of sound change, including the existence of neogrammarian regularity and the life cycle of phonological processes. Ultimately, we may expect the best phonological explanations to operate in amphichronic fashion, with synchronic and diachronic inference feeding each other. There are, however, no methodological shortcuts to such explanations: they will be discovered only by the 
ordinary labour-intensive, unpredictable, intermittently frustrating means of hypothesis formation and testing.

\section{References}

Anderson, Stephen R. (1988). 'Morphological change', in Frederick J. Newmeyer (ed.), Linguistics: The Cambridge Survey (vol. 1). Cambridge: Cambridge University Press, 324-62.

Baese-Berk, Melissa and Matthew Goldrick (2008). 'Mechanisms of interaction in speech production', Language and Cognitive Processes 24: 527-54.

Baker, Adam, Diana Archangeli, and Jeff Mielke (2011). 'Variability in American English sretraction suggests a solution to the actuation problem', Language Variation and Change 23: 347-74.

Bermúdez-Otero, Ricardo (1999). Constraint interaction in language change: quantity in English and Germanic [Opacity and globality in phonological change]. Doctoral dissertation, University of Manchester and Universidad de Santiago de Compostela. Available at http://www.bermudez-otero.com/PhD.pdf.

- (2007). 'Diachronic phonology', in Paul de Lacy (ed.), The Cambridge handbook of phonology. Cambridge: Cambridge University Press, 497-517.

- (2010). 'Morphologically conditioned phonetics? Not proven'. Paper given at On Linguistic Interfaces II, Belfast, 2 December 2010. Handout available at http://www.bermudezotero.com/Belfast_handout.pdf.

- (2011). 'Cyclicity', in Marc van Oostendorp, Colin J. Ewen, Elizabeth Hume, and Keren Rice (eds), The Blackwell companion to phonology (vol. 4). Malden, MA: WileyBlackwell, 2019-48.

- (2012). 'The architecture of grammar and the division of labour in exponence', in Jochen Trommer (ed.), The morphology and phonology of exponence. Oxford: Oxford University Press, 8-83.

Bermúdez-Otero, Ricardo and April McMahon (2006). 'English phonology and morphology', in Bas Aarts and April McMahon (eds), The bandbook of English linguistics. Oxford: Blackwell, 382-410.

Bermúdez-Otero, Ricardo and Graeme Trousdale (2012). 'Cycles and continua: on unidirectionality and gradualness in language change', in Terttu Nevalainen and Elizabeth Closs Traugott (eds), The Oxford handbook of the history of English. New York: Oxford University Press, 691-720.

Blevins, Juliette (2004). Evolutionary phonology: the emergence of sound patterns. Cambridge: Cambridge University Press.

Bloomfield, Leonard (1933). Language. New York: Holt. 
Boersma, Paul (2009a). 'Cue constraints and their interaction in phonological perception and production', in Paul Boersma and Silke Hamann (eds), Phonology in perception. Berlin: Mouton de Gruyter, 55-109.

- (2009b). 'A programme for bidirectional phonology and phonetics and their acquisition and evolution'. Ms. Amsterdam: Institute of Phonetic Sciences, University of Amsterdam. Available at http://www.fon.hum.uva.nl/paul/papers/BiPhon19.pdf.

- (2012). 'Modeling phonological category learning', in Abigail C. Cohn, Cécile Fougeron, and Marie K. Huffman (eds), The Oxford handbook of laboratory phonology. Oxford: Oxford University Press, 207-18.

Boersma, Paul and Bruce Hayes (2001). 'Empirical tests of the Gradual Learning Algorithm', Linguistic Inquiry 32: 45-86.

Booij, Geert (1995). The phonology of Dutch. Oxford: Clarendon Press.

Booij, Geert and Jerzy Rubach (1987). 'Postcyclic versus postlexical rules in Lexical Phonology', Linguistic Inquiry 18: 1-44.

Broś, Karolina (2012). Survival of the fittest: fricative lenition in English and Spanish from the perspective of Optimality Theory. $\mathrm{PhD}$ dissertation, University of Warsaw.

Bybee, Joan (2001). Phonology and language use. Cambridge: Cambridge University Press.

Cho, Taehong (2001). 'Effects of morpheme boundaries on intergestural timing: evidence from Korean', Phonetica 58: 129-62.

Darlington, Richard B. (1970). 'Is kurtosis really “peakedness”?' The American Statistician 24: 19-22.

Davis, Garry W. (2008). 'Toward a progression theory of the Old High German Consonant Shift', Journal of Germanic Linguistics 20: 197-241.

Dinkin, Aaron J. (2008). 'The real effect of word frequency on phonetic variation', in Joshua Tauberer, Aviad Eilam, and Laurel MacKenzie (eds), Proceedings of the $31^{\text {st }}$ Annual Penn Linguistics Colloquium (University of Pennsylvania Working Papers in Linguistics 14.1). Philadelphia: Penn Linguistics Club, 97-106. Available at http://repository.upenn.edu/pwpl/vol14/iss1/8/.

Dresher, B. Elan and Xi Zhang (2005). 'Contrast and phonological activity in Manchu vowel systems', Canadian Journal of Linguistics 50: 45-82.

Ellis, Lucy and William J. Hardcastle (2002). 'Categorical and gradient properties of assimilation in alveolar to velar sequences: evidence from EPG and EMA data', Journal of Phonetics 30: 373-96.

Erker, Daniel (2012). 'Of categories and continua: relating discrete and gradient properties of sociophonetic variation', University of Pennsylvania Working Papers in Linguistics 18 (Issue 2, Selected papers from NWAV 40): 11-20. Available at http://repository.upenn.edu/pwpl/vol18/iss2/3.

Fruehwald, Josef (2012). 'Phonological involvement in phonetic change'. Ms. Philadelphia: University of Pennsylvania. Available at http://www.ling.upenn.edu/_joseff/papers/fruehwald_proposal.pdf. 
Garrett, Andrew and Juliette Blevins (2009). 'Analogical morphophonology', in Kristin Hanson and Sharon Inkelas (eds), The nature of the word: essays in honor of Paul Kiparsky. Cambridge, MA: The MIT Press, 527-45.

Goldrick, Matthew, H. Ross Baker, Amanda Murphy, and Melissa Baese-Berk (2011). 'Interaction and representational integration: evidence from speech errors', Cognition 121: 58-72.

Guy, Gregory R. (1991a). 'Contextual conditioning in variable lexical phonology', Language Variation and Change 3: 223-39.

- (1991b). 'Explanation in variable phonology: an exponential model of morphological constraints', Language Variation and Change 3: 1-22.

- (1996). 'Form and function in linguistic variation', in Gregory R. Guy, Crawford Feagin, Deborah Schiffrin, and John Baugh (eds), Towards a social science of language: papers in bonor of William Labov (vol. 1). Amsterdam: John Benjamins, 221-52.

Hale, Mark, Madelyn Kissock, and Charles Reiss (2006). 'Microvariation, variation, and the features of universal grammar', Lingua 117: 645-65.

Halle, Morris and Jean-Roger Vergnaud (1987). 'Stress and the cycle', Linguistic Inquiry 18: 4584.

Hamann, Silke (2009). 'The learner of a perception grammar as a source of sound change', in Paul Boersma and Silke Hamann (eds), Phonology in perception. Berlin: Mouton de Gruyter, 111-49.

Harrington, Jonathan (2006). 'An acoustic analysis of "happy-tensing” in the Queen's Christmas broadcasts', Journal of Phonetics 34: 439-57.

Hayes, Bruce (1999). 'Phonetically-driven phonology: the role of Optimality Theory and inductive grounding', in Michael Darnell et al. (eds), Functionalism and formalism in linguistics (vol. 1). Amsterdam: John Benjamins, 243-85.

- (2000). 'Gradient well-formedness in Optimality Theory', in Joost Dekkers, Frank van der Leeuw, and Jeroen van de Weijer (eds), Optimality Theory: phonology, syntax, and acquisition. Oxford: Oxford University Press, 88-120.

Hock, Hans Heinrich (1991). Principles of bistorical linguistics $\left(2^{\text {nd }}\right.$ edn). Berlin: Mouton de Gruyter.

Honeybone, Patrick (2008). 'Lenition, weakening and consonantal strength: tracing concepts through the history of phonology', in Joaquim Brandão de Carvalho, Tobias Scheer, and Philippe Ségéral (eds), Lenition and fortition. Berlin: Mouton de Gruyter, 9-93.

Hyman, Larry (1975). Phonology: theory and analysis. New York: Holt, Rinehart and Winston. - (1976). 'Phonologization', in Alphonse Juilland, A. M. Devine, and Laurence D. Stephens (eds), Linguistic studies offered to Joseph Greenberg on the occasion of bis sixtieth birthday. Saratoga, CA: Anma Libri, 407-18.

Iverson, Gregory K. and Joseph C. Salmons (2006). 'Fundamental regularities in the Second Consonant Shift', Journal of Germanic Linguistics 18: 45-70. 
Jackendoff, Ray (1975). 'Morphological and semantic regularities in the lexicon', Language 51: 639-71.

Jakobson, Roman (1929). 'Remarques sur l'évolution phonologique du russe comparée à celle des autres langues slaves', Travaux du Cercle Linguistique de Prague 2.

Kawahara, Shigeto (2011). 'Experimental approaches in theoretical phonology', in Marc van Oostendorp, Colin J. Ewen, Elizabeth Hume, and Keren Rice (eds), The Blackwell companion to phonology (vol. 4). Malden, MA: Wiley-Blackwell.

Kiparsky, Paul (1973). '"Elsewhere” in phonology', in Stephen R. Anderson and Paul Kiparsky (eds), A Festschrift for Morris Halle. New York: Holt, Rinehart and Winston, 93-106.

- (1982). 'Lexical Morphology and Phonology', in In-Seok Yang for the Linguistic Society of Korea (ed.), Linguistics in the morning calm: selected papers from SICOL-1981 (vol. 1). Seoul: Hanshin Publishing Company, 3-91.

- (1988). 'Phonological change', in Frederick J. Newmeyer (ed.), Linguistics: the Cambridge survey (vol. 1). Cambridge: Cambridge University Press, 363-415.

- (1995). 'The phonological basis of sound change', in John A. Goldsmith (ed.), The bandbook of phonological theory. Oxford: Blackwell, 640-70.

- (2000). 'Opacity and cyclicity', in Nancy A. Ritter (ed.), A review of Optimality Theory. Special issue, The Linguistic Review 17: 351-67.

- (2006). 'The Amphichronic Program vs. Evolutionary Phonology', Theoretical Linguistics 32: 217-36.

Kruszewski, Mikołaj (1881). Ueber die Lautabwechslung. Kazan: Universitätsbuchdruckerei. Available in English (1995), 'On sound alternation', translated by Robert Austerlitz, in Writings in general linguistics (ed. Konrad Koerner), Amsterdam: John Benjamins, 3-34.

Labov, William (1989). 'Exact description of the speech community: short $a$ in Philadelphia', in Ralph W. Fasold and Deborah Schiffrin (eds), Language change and variation.

Amsterdam: John Benjamins, 1-57.

- (1994). Principles of linguistic change: internal factors. Oxford: Blackwell.

- (2007). 'Transmission and diffusion', Language 83: 344-87.

- (2010). Principles of linguistic change: cognitive and cultural factors. Malden, MA: WileyBlackwell.

Lignos, Constantine (2012). 'Productivity in analogical change'. Paper given at the Manchester and Salford New Researchers Forum in Linguistics, Manchester, 3 November 2012. Slides available at http://www.seas.upenn.edu/_lignos/talks/MancSalFiL_Postnasal_Deletion_Lignos_web .pdf.

MacKenzie, Laurel (2013). 'Variation in English auxiliary realization: a new take on contraction', Language Variation and Change 25 (1).

Marr, David (1982). Vision: a computational investigation into the buman representation and processing of visual information. San Francisco: W. H. Freeman. 
Maye, Jessica, Janet F. Werker, and LouAnn Gerken (2002). 'Infant sensitivity to distributional information can affect phonetic discrimination', Cognition 82: B101-B111.

Moreton, Elliott (2008). 'Analytic bias and phonological typology', Phonology 25: 83-127.

Moreton, Elliott and Joe Pater (forthcoming-a). 'Structure and substance in artificialphonology learning. Part I: Structure', Language and Linguistics Compass.

- (forthcoming-b). 'Structure and substance in artificial-phonology learning. Part II: Substance', Language and Linguistics Compass.

Munson, Benjamin and Nancy Pearl Solomon (2004). 'The influence of phonological neighborhood density on vowel articulation', Journal of Speech, Language, and Hearing Research 47: 1048-1058.

Myers, Scott (2000). 'Boundary disputes: the distinction between phonetic and phonological sound patterns', in Noel Burton-Roberts, Philip Carr, and Gerard Docherty (eds), Phonological knowledge: conceptual and empirical issues. Oxford: Oxford University Press, 245-72.

Ohala, John J. (1981). 'The listener as a source of sound change', in Carrie S. Masek, Roberta A. Hendrick, and Mary Frances Miller (eds), Papers from the parasession on language and bebavior (Chicago Linguistic Society 17). Chicago: Chicago Linguistics Society, 178203.

Pater, Joe and Elliott Moreton (2012). 'Structurally biased phonology: complexity and learning in typology', The EFL Journal (Journal of the he English and Foreign Languages University, Hyderabad) 3: 1-44.

Pierrehumbert, Janet (2002). 'Word-specific phonetics', in Carlos Gussenhoven and Natasha Warner (eds), Laboratory Phonology 7. Berlin: Mouton de Gruyter, 101-39.

PNC = Philadelphia Neighborhood Corpus of LING560 Studies, 1971-2010. With the support of NSF contract 921643 to William Labov. http://fave.ling.upenn.edu/pnc.html.

Prince, Alan and Paul Smolensky (1993). Optimality Theory: constraint interaction in generative grammar (Technical Reports of the Rutgers University Center for Cognitive Science, RuCCS-TR-2). New Brunswick, NJ: Rutgers University Center for Cognitive Science. Published (2004), Oxford: Blackwell.

Ramsammy, Michael (2012). 'Word-final nasal velarisation in Spanish', Journal of Linguistics.

- (forthcoming). 'The life cycle of phonological processes: accounting for dialectal microtypologies', Linguistics and Language Compass.

Rapp, Brenda and Matthew Goldrick (2000). 'Discreteness and interactivity in spoken word production', Psychological Review 107: 460-99.

Robinson, Orrin Warner (1976). 'A “scattered” rule in Swiss German', Language 52: 148-62.

Sankoff, Gillian and Hélène Blondeau (2007). 'Language change across the lifespan: /r/ in Montreal French', Language 83: 560-88.

Saussure, Ferdinand de (1916). Cours de linguistique générale (ed. by Charles Bally and Albert Sechehaye, in collaboration with Albert Reidlinger). Lausanne and Paris: Librairie Payot. 
Scheer, Tobias (2011). A guide to morphosyntax-phonology interface theories: how extraphonological information is treated in phonology since Trubetzkoy's Grenzsignale. Berlin: Mouton de Gruyter.

Schmidt, Johannes (1872). Die Verwandtschaftsverbältnisse der indogermanischen Sprachen. Weimar: H. Böhlau.

Schuchardt, Hugo (1885). Über die Lautgesetze: gegen die Junggrammatiker. Berlin: Oppenheim. Available in English (1972), 'On sound laws: against the neogrammarians', in Theo Vennemann and Terence H. Wilbur (eds), Schuchardt, the neogrammarians, and the transformational theory of phonological change: four essays, Frankfurt am Main: Athenäum Verlag, 41-72.

Sebregts, Koen and Patrycja Strycharczuk (2012). 'Phonetically gradient allomorphy: the case of the Dutch past tense'. Paper given at the $20^{\text {th }}$ Manchester Phonology Meeting, 24 May 2012. Available at http://personalpages.manchester.ac.uk/staff/patrycja.strycharczuk/CV_files/20mfmslides .pdf.

Smolensky, Paul (2006). 'Computational levels and integrated connectionist/symbolic explanation', in Paul Smolensky and Géraldine Legendre (eds), The harmonic mind: from neural computation to optimality-theoretic grammar (vol. 2). Cambridge, MA: The MIT Press, 503-92.

Sóskuthy, Márton (2011). 'Why phonologists should care about exemplar theory'. Paper given at the $19^{\text {th }}$ Manchester Phonology Meeting, 19 May 2011. Available at http://www.lel.ed.ac.uk/ s0954634/soskuthy11_mfm19.zip.

Sproat, Richard and Osamu Fujimura (1993). 'Allophonic variation in English /1/ and its implications for phonetic implementation', Journal of Phonetics 21: 291-311.

Strycharczuk, Patrycja (2012). Phonetics-phonology interactions in pre-sonorant voicing. $\mathrm{PhD}$ thesis, University of Manchester. Available at http://ling.auf.net/lingbuzz/001645.

Turton, Danielle (2012). 'The darkening of English /1/: a Stochastic Stratal OT analysis'. Ms.: University of Manchester. Available at http://ling.auf.net/lingbuzz/001524.

Vennemann, Theo (1972). 'Phonetic analogy and conceptual analogy', in Theo Vennemann and Terence H. Wilbur (eds), Schuchardt, the neogrammarians, and the transformational theory of phonological change: four essays. Frankfurt am Main: Athenäum Verlag, 181-204.

Wang, William S-Y. (1969). 'Competing changes as a cause of residue', Language 45: 9-25.

Yang, Charles (2005). 'On productivity', Linguistic Variation Yearbook 5: 265-302.

Yuan, Jiahong and Mark Liberman (2009). 'Investigating /1/ variation in English through forced alignment', INTERSPEECH 2009: $10^{\text {th }}$ Annual Conference of the International Speech Communication Association, Brighton, UK, 6-10 September 2009. Brighton: International Speech Communication Association, 2215-18.

- (2011). '/1/ variation in American English: a corpus approach', Journal of Speech Sciences 1: $35-46$. 
